\title{
ASAP Progress and Expenditure Report for the Month of February 1-29, 1996
}

R. E. Twogood, J. M. Brase, D. H. Chambers, D. M. Mantrom, M. G. Miller, M. J. Newman, H. F. Robey, M. Vigars

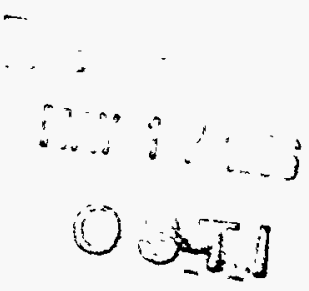

March 20, 1996

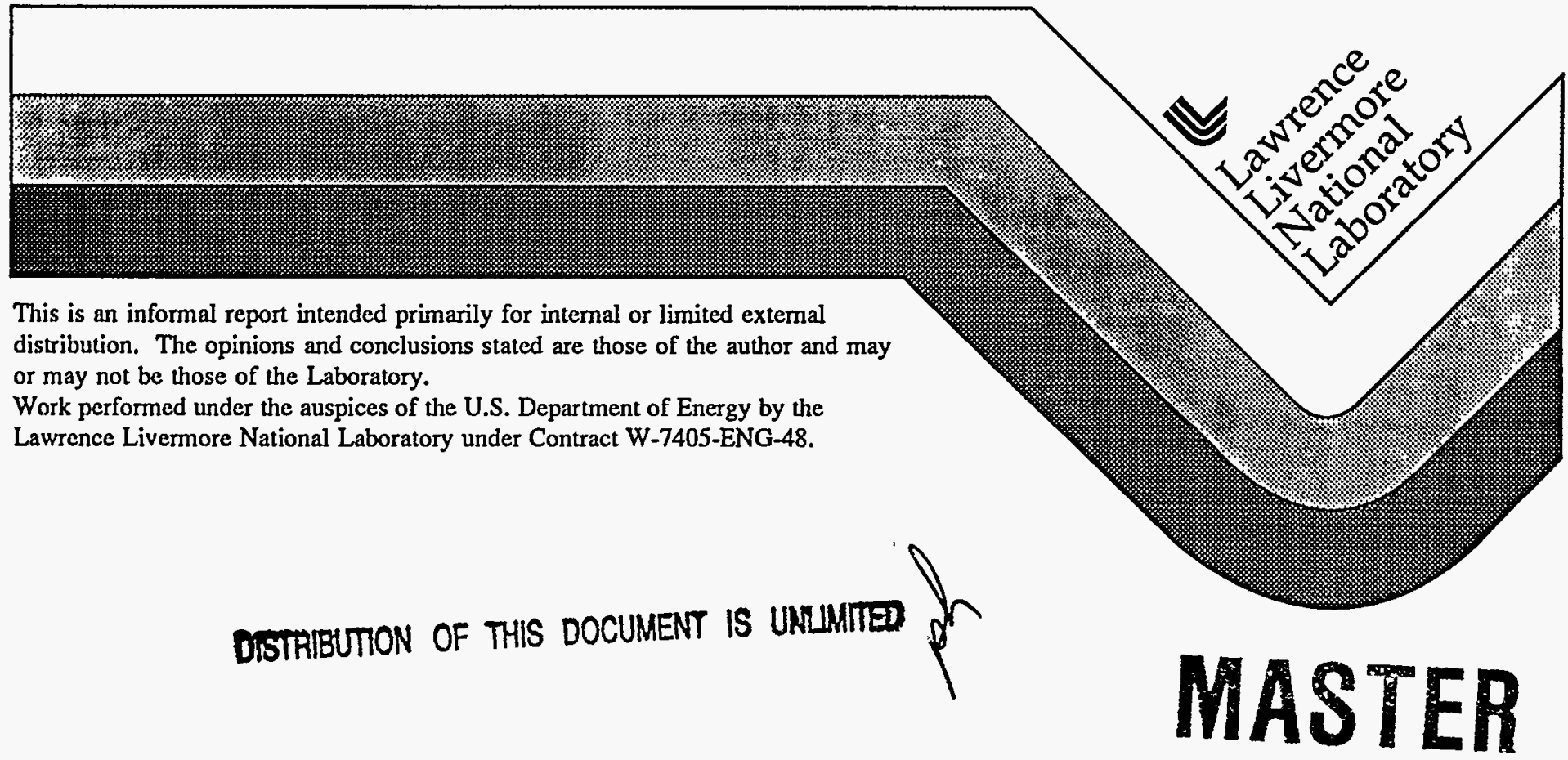




\section{DISCLAIMER}

This document was prepared as an account of work sponsored by an agency of the United States Government. Neither the United States Government nor the University of California nor any of their employees, makes any warranty, express or implied, or assumes any legal liability or responsibility for the accuracy, completeness, or usefulness of any information, apparatus, product, or process disclosed, or represents that its use would not infringe privately owned rights. Reference herein to any specific commercial products, process, or service by trade name, trademark, manufacturer, or otherwise, does not necessarily constitute or imply its endorsement, recommendation, or favoring by the United States Government or the University of California. The views and opinions of authors expressed herein do not necessarily state or reflect those of the United States Government or the University of Californiz, and shall not be used for advertising or product endorsement purposes.

This report has been reproduced directly from the best available copy.

Available to DOE and DOE contractors from the Office of Scientific and Technical Information

P.O. Box 62, Oak Ridge, TN 37831

Prices available from (615) 576-8401, FTS 626-8401

Available to the public from the

National Technical Information Service

U.S. Department of Commerce 5285 Port Rojal Rd. Springfield, VA 22161 


\section{ASAP PROGRESS and EXPENDITURE \\ REPORT \\ for the Month of February 1-29, 1996}

Organization: LLNL

Project: $\quad$ P.LLN.1010 Airborne RAR/SAR

Principal Investigator: $\quad$ Mark G. Miller

Long Term Objectives:

The RAR/SAR is a high-priority radar system for the joint US/UK Program. Based on previous experiment results and coordination with the UK, specifications needed for future radar experiments were identified as follows: dual polarimetric ( $\mathrm{HH}$ and VV) with medium to high resolution in SAR mode. Secondary airborne installation requirements included; high power (circa 10kw) and SLAR capability to emulate Tupelev-134 type system; initially $x$-band but easily extendible to other frequencies.

In FY 96 we intend to enhance the radar system's capabilities by providing a second polarization (VV), spotlight imaging mode, extended frequency of operation to include S-band, increase power, and interface to an existing infrared sensor.

Short Term Objectives:

- Continue to evaluate and characterize the radar system.

- Upgrade navigation and real-time processing capability to refine motion compensation.

- Upgrade to dual polarimetry (add VV).

- Develop a "spot-light" mode capability.

Accomplishments THIS reporting period:

No accomplishments to report this period due to insufficient funds.

Other Issues or Concerns: (None)

Project Budget Estimate (FY), Monthly Actual and YTD expenditures for WUA number P.LLN.1010:

\begin{tabular}{|c|c|c|c|c|c|c|c|c|c|}
\hline & \multicolumn{6}{|c|}{ DIRECT LABOR } & \multicolumn{2}{|c|}{ ODC } & \multirow{3}{*}{ TOTAL } \\
\hline & \multicolumn{2}{|c|}{ Management } & \multicolumn{2}{|c|}{ Technical } & \multicolumn{2}{|c|}{ Support } & \multirow{2}{*}{$\begin{array}{c}\text { Procure- } \\
\text { ment }\end{array}$} & \multirow[t]{2}{*}{ Travel } & \\
\hline & $\overline{\mathrm{M} / \mathrm{M}}$ & Cost & $\overline{\mathbf{M} / \mathbf{M}}$ & Cost & $\bar{M} / \mathbf{M}$ & $\overline{\text { Cost }}$ & & & \\
\hline $\begin{array}{l}\text { Project } \\
\text { Budget }\end{array}$ & 0 & $\mathbf{0}$ & TBD & TBD & $\mathbf{0}$ & $\mathbf{0}$ & TBD & TBD & TBD \\
\hline Actual & 0 & 0 & 1.9 & 28.2 & 0 & 0 & 9.7 & 0.1 & 38.0 \\
\hline YTD & 0 & 0 & 9.0 & 128.4 & 0 & 0 & 76.5 & 1.3 & 206.2 \\
\hline
\end{tabular}


Organization: LLNL

Program: $\quad$ P.LLN.1020 Radar Data Processor

Principal Investigator: James M. Brase

Long Term Objectives:

The objectives of the Radar Data Processor development for the airborne RAR/SAR are:

- Provide real-time SAR image formation for immediate feedback on experiment operations.

- Provide a full-resolution SAR mode for off-line processing in the field.

- Provide limited image enhancement and analysis for field experiments.

The principal task in FY96 is to implement a new version of the RDP for the UK Experimental Surveillance Radar (ESR).

Short Term Objectives:

- Complete SGI-based RDP hardware design

- Prepare for CDR in UK (schedule TBD)

- Specify SAR reconstruction software

Accomplishments THIS reporting period:

- Physical characteristics of SGI design were identified and discussed with DRA Malvern.

- Hardware design was completed and procurement requisitions prepared.

Other Issues or Concerns: None

Project Budget Estimate (FY), Monthly Actual and YTD expenditures for WUA number P.LLN.1020:

\begin{tabular}{|c|c|c|c|c|c|c|c|c|c|}
\hline & \multicolumn{6}{|c|}{ DIRECT LABOR } & \multicolumn{2}{|c|}{ ODC } & \multirow{3}{*}{ TOTAL } \\
\hline & \multicolumn{2}{|c|}{ Management } & \multicolumn{2}{|c|}{ Technical } & \multicolumn{2}{|c|}{ Support } & \multirow{2}{*}{$\begin{array}{c}\text { Procure- } \\
\text { ment }\end{array}$} & \multirow[t]{2}{*}{ Travel } & \\
\hline & $\mathbf{M} / \mathbf{M}$ & Cost & $\mathbf{M} / \mathbf{M}$ & Cost & $\mathbf{M} / \mathbf{M}$ & Cost & & & \\
\hline $\begin{array}{l}\text { Project } \\
\text { Budget }\end{array}$ & 0 & 0 & TBD & TBD & 0 & 0 & TBD & TBD & TBD \\
\hline Actual & 0 & 0 & 1.2 & 31.9 & $\mathbf{0}$ & $\mathbf{0}$ & 1.6 & 0.0 & 33.5 \\
\hline YTD & $\mathbf{0}$ & 0 & 4.5 & 94.2 & $\mathbf{0}$ & 0 & $(27.6)$ & 0.0 & 66.6 \\
\hline
\end{tabular}


Organization: LLNL

Program: P.LLN.1030 Ground-based SAR Signal Processing Workstation

Principal Investigator: James M. Brase

Long Term Objectives:

The ground-based signal processing workstation provides four classes of signal processing capabilities:

- Tools for real-aperture radar (RAR) image formation and data management.

- SAR image formation: our standard dark SAR processor and our new Precision SAR processor (PSAR).

- Doppler filtering, local normalization, and matched filter codes for LGA imagery.

- Image enhancement, feature extraction, and detection codes for SAR imagery.

Our FY96 objectives are to extend the LGA software tools to incorporate locally optimal (LO) detectors and to complete development of PSAR, particularly its motion and Doppler processing compensation capabilities.

Short Term Objectives:

- Complete and distribute catalog of priority imagery from July 95 AUTEC experiment.

- Complete report on clutter modeling. and LO detection software tools.

- Complete PSAR software design.

Accomplishments THIS reporting period:

- All writing for AUTEC imagery catalog completed; we expected to be ready for distribution in March.

- Draft report on LO detection software completed; undergoing review; completed report should be delivered in April.

- Initial PSAR software requirements analysis reviewed.

Other Issues or Concerns: None

Project Budget Estimate (FY), Monthly Actual and YTD expenditures for WUA number P.LLN.1030:

\begin{tabular}{|c|c|c|c|c|c|c|c|c|c|}
\hline & \multicolumn{6}{|c|}{ DIRECT LABOR } & \multicolumn{2}{|l|}{ ODC } & \multirow{3}{*}{ TOTAL } \\
\hline & \multicolumn{2}{|c|}{ Management } & \multicolumn{2}{|c|}{ Technical } & \multicolumn{2}{|c|}{ Support } & \multirow{2}{*}{$\begin{array}{l}\text { Procure- } \\
\text { ment }\end{array}$} & \multirow[t]{2}{*}{ Travel } & \\
\hline & $\mathbf{M} / \mathbf{M}$ & Cost & $\mathrm{M} / \mathrm{M}$ & Cost & $\mathbf{M} / \mathbf{M}$ & Cost & & & \\
\hline $\begin{array}{l}\text { Project } \\
\text { Budget }\end{array}$ & 0 & 0 & TBD & TBD & 0 & 0 & TBD & TBD & TBD \\
\hline Actual & 0 & 0 & 1.6 & 24.7 & 0 & 0 & $\mathbf{0}$ & 0.0 & 24.7 \\
\hline YTD & 0 & 0 & 3.0 & 48.1 & 0 & 0 & (0.1) & 0.0 & 48.0 \\
\hline
\end{tabular}


Organization: LLNL

\section{Program: $\quad$ P.LLN.1040 Static Airborne Radar}

Principal Investigator: Michael J. Newman and Mark L. Vigars

Long Term Objectives:

- Maintenance, and storage of aerostats and related systems.

- Engineering modifications and support as needed for two aerostat mooring systems (mobile land based and East coast ship based).

- Development of a stabilized platform and high resolution radar system for deployment by the aerostat.

- Utilization of these systems in field experiments in the UK/US program.

Short Term Objectives:

- Develop joint plan with UK for potential aerostat usage.

- Terminate all FY96 development work on aerostats.

Accomplishments THIS reporting period:

Per discussions with the ASAP project manager, LLNL has taken steps to terminate the aerostat development work for FY96. The building 531 work at LLNL is being stopped, and the facility will likely be vacated if possible. We will begin discussions with the UK on a joint plan for FY97 and later.

Other Issues or Concerns: None

Project Budget Estimate (FY), Monthly Actual and YTD expenditures for WUA number P.LLN.1040:

\begin{tabular}{|c|c|c|c|c|c|c|c|c|c|}
\hline & \multicolumn{6}{|c|}{ DIRECT LABOR } & \multicolumn{2}{|l|}{ ODC } & \multirow{3}{*}{ TOTAL } \\
\hline & \multicolumn{2}{|c|}{ Management } & \multicolumn{2}{|c|}{ Technical } & \multicolumn{2}{|c|}{ Support } & \multirow{2}{*}{$\begin{array}{l}\text { Procure- } \\
\text { ment }\end{array}$} & \multirow[t]{2}{*}{ Travel } & \\
\hline & $\mathrm{M} / \mathrm{M}$ & Cost & $\mathbf{M} / \mathbf{M}$ & Cost & $\mathrm{M} / \mathrm{M}$ & Cost & & & \\
\hline $\begin{array}{l}\text { Project } \\
\text { Budget }\end{array}$ & 0 & $\mathbf{0}$ & TBD & TBD & 0 & 0 & TBD & TBD & TBD \\
\hline Actual & 0 & 0 & 1.8 & 30.9 & 0 & 0 & 10.8 & 0.0 & 41.7 \\
\hline YTD & 0 & 0 & 10.0 & 167.8 & 0 & 0 & 84.0 & 0.0 & 251.8 \\
\hline
\end{tabular}


Organization: LLNL

Program: P.LLN.1060 Radar Field Experiments

Principal Investigator: David Mantrom

Long Term Objectives:

Continue planning for FY96 field experiments, including MTF Experiment and West Coast Clutter Flights.

Short Term Objectives:

Finalized Revised Plan for West Coast Clutter/IW Flights

1996 MTF Test Requirements/Test Concept Document

\section{Recent Accomplishments:}

We have concentrated our FY96 experiment planning on West Coast Clutter/IW flights throughout the year and a MTF experiment.

A revised document describing the plan for West Coast Clutter/IW flights over five NDBC meteorological buoys off the coast of Southern California and possible MTF experiment sites is being reviewed internally.

A draft document describing conceptual plans for a MTF experiment has been written and is being reviewed internally: We have explored the possible use of the Scripps surface scan Doppler sonar for surface current measurement over a $300 \mathrm{~m}$ aperture and it may be available for limited use in the MTF experiment.

We were informed by JHU/APL that the NAWC/ERIM P-3 XLC SAR was selected for the primary radar data collection in the Navy's Emerald II experiment. (The LLNL/Hughes AETB/SAR was the other candidate.) We subsequently attended two Emerald meetings, one a test planning meeting.

Other Issues or Concerns:

COPE environmental data request approval by ASAP Program Manager.

Project Budget Estimate (FY), Monthly Actual and YTD expenditures for WUA number P.LLN.1060:

\begin{tabular}{|c|c|c|c|c|c|c|c|c|c|}
\hline & \multicolumn{6}{|c|}{ DIRECT LABOR } & \multicolumn{2}{|c|}{ ODC } & \multirow{3}{*}{ TOTAL } \\
\hline & \multicolumn{2}{|c|}{ Management } & \multicolumn{2}{|c|}{ Technical } & \multicolumn{2}{|c|}{ Support } & \multirow{2}{*}{$\begin{array}{c}\text { Procure- } \\
\text { ment }\end{array}$} & \multirow[t]{2}{*}{ Travel } & \\
\hline & $\mathrm{M} / \mathrm{M}$ & Cost & $\mathbf{M} / \mathbf{M}$ & Cost & $\mathrm{M} / \mathrm{M}$ & Cost & & & \\
\hline $\begin{array}{l}\text { Project } \\
\text { Budget }\end{array}$ & 0 & 0 & TBD & TBD & $\mathbf{0}$ & 0 & TBD & TBD & TBD \\
\hline Actual & $\mathbf{0}$ & $\mathbf{0}$ & 0.8 & 20.5 & 0 & 0 & 7.3 & 0.0 & 27.8 \\
\hline YTD & 0 & 0 & 4.5 & 109.3 & 0 & 0 & 186.8 & 0.0 & 296.1 \\
\hline
\end{tabular}


Organization: LLNL

Program: $\quad$ P.LLN.1070 Data Analysis and Defection Theory

Principal Investigator: James M. Brase

Long Term Objectives:

The overall goal is to develop a model for the detectability of internal wave wakes in radar images. Our detection models have four parts:

- A signal model describing the amplitude and shape of the image model as a function of target, environmental, and radar system parameters.

- A clutter model which describes the amplitude distribution and correlation structure of the ambient image clutter.

- Detection algorithms which prescribe the method for making detection decisions.

- A performance analysis methodology.

Our FY96 objectives concentrate on extending our signal and clutter models and on using the models to define optimal detection on algorithms for non-Gaussian clutter.

Short Term Objectives:

- Evaluate SMS results presented at January program meeting.

- Write report on performance of locally optimal detectors on LGA RAR imagery.

- Complete summary report on wake detection in database.

- Write report on clutter models and detector performance in Overview 1 SAR imagery.

- Complete report on MTF analysis through LL94.

Accomplishments THIS reporting period:

- Completed an analysis of matched filter SNR performance for SOS 91 images P3, P4, P7 which compared the SNR's obtained by SMS to those obtained on LLNL processed images. The SNR's were found to be equivalent. Any interpretation of these results cannot, therefore, be based on improved image quality. The SNR's in these cases are essentially at the false-alarm level. These results will be discussed at a meeting in March.

- Work continued on reports (2) and (3) above which should be completed in April.

- A draft report was completed by R. Manasse suggesting a new non-parametric image quality metric for quantitative evaluation of image enhancement techniques. The report is being reviewed at LLNL.

Other Issues or Concerns: None

Project Budget Estimate (FY), Monthly Actual and YTD expenditures for WUA number P.LLN.1070:

\begin{tabular}{|c|c|c|c|c|c|c|c|c|c|}
\hline & \multicolumn{6}{|c|}{ DIRECT LABOR } & \multicolumn{2}{|c|}{ ODC } & \multirow{3}{*}{ TOTAL } \\
\hline & \multicolumn{2}{|c|}{ Management } & \multicolumn{2}{|c|}{ Technical } & \multicolumn{2}{|c|}{ Support } & \multirow{2}{*}{$\begin{array}{c}\text { Procure- } \\
\text { ment }\end{array}$} & \multirow[t]{2}{*}{ Travel } & \\
\hline & $\bar{M} / \mathbf{M}$ & Cost & $\bar{M} / \mathbf{M}$ & Cost & $\overline{\mathrm{M} / \mathrm{M}}$ & Cost & & & \\
\hline $\begin{array}{l}\text { Project } \\
\text { Budget }\end{array}$ & 0 & 0 & TBD & TBD & 0 & 0 & TBD & TBD & TBD \\
\hline Actual & 0 & 0 & 5.5 & 99.6 & 0 & 0 & 14.4 & 3.7 & 117.7 \\
\hline YTD & 0 & $\mathbf{0}$ & 17.5 & 311.5 & 0 & 0 & 423.1 & 5.6 & 740.2 \\
\hline
\end{tabular}


Organization: LLNL

Program: P.LLN.1080 Management

Principal Investigator: Richard E. Twogood

Long Term Objectives:

Provide ongoing management oversight and support for the Joint UK/US Radar Program in addition to other consultant and management services (Wells, Manasse, etc.). All administrative support for UK/US program included in this work unit. (clerical, administrator, facilities).

Short Term Objectives:

- Execute all administrative and management actions required to keep the UK/US Program functioning smoothly. For FY96 Q1, this includes dealing with all short-term issues arising from the continuing resolution(s).

Accomplishments THIS reporting period:

All management functions for the UK/US Radar Program, plus the related functions and contract management, were successfully performed. Although the FY96 budget has not been firmly set by ISSO, LLNL has taken initial steps to shut down certain facilities and activities based on discussions with ISSO.

A meeting involving Carl Klele, Donna Kulla, Rick Twogood, and Andy Millunzi (of DOE) was held at ISSO on 2/16/96. DOE and ISSO will work toward a MOU. No issues requiring action by LLNL were identified.

Tony Wells continued his efforts coordinating the AIRMS system issues with ASAP, ARPA, and other DoD organizations, in addition to his direct support for UK/US Radar issues.

Other Issues or Concerns:

The \$2M MIPR received in February 1996 paid all costs plus commitments for Dec. 95, Jan. 96, and Feb. 96. It also permitted LLNL to begin the procurement process for the ESR processor and the VV-upgrade of the Airborne Testbed (AETB) radar. LLNL is again at risk effective $3 / 1 / 96$ - we will require additional funds by April 1 or we must further delay all development activities, including the ESR and the VV-upgrade.

The cost for the ERIM contract, which accrued in FY96 but was for work conducted in FY95, have been moved to a separate account (at the request of the ASAP Program Manager) to be covered by FY95 funds.

Project Budget Estimate (FY), Monthly Actual and YTD expenditures for WUA number P.LLN.1080:

\begin{tabular}{|c|c|c|c|c|c|c|c|c|c|}
\hline & \multicolumn{6}{|c|}{ DIRECT LABOR } & \multicolumn{2}{|c|}{ ODC } & \multirow{3}{*}{ TOTAL } \\
\hline & \multicolumn{2}{|c|}{ Management } & \multicolumn{2}{|c|}{ Technical } & \multicolumn{2}{|c|}{ Support } & \multirow{2}{*}{$\begin{array}{c}\text { Procure- } \\
\text { ment }\end{array}$} & \multirow[t]{2}{*}{ Travel } & \\
\hline & $\mathrm{M} / \mathrm{M}$ & Cost & $\mathrm{M} / \mathrm{M}$ & Cost & $\mathrm{M} / \mathrm{M}$ & Cost & & & \\
\hline $\begin{array}{l}\text { Project } \\
\text { Budget }\end{array}$ & TBD & TBD & 0 & $\mathbf{0}$ & TBD & TBD & TBD & TBD & TBD \\
\hline Actual & 0.1 & 2.9 & 0 & $\mathbf{0}$ & 1.9 & 17.2 & (152.6) & 11.1 & $(120.0)$ \\
\hline YTD & 4.0 & 124.3 & 0 & 0 & 5.0 & 43.0 & 594.7 & 35.4 & 797.4 \\
\hline
\end{tabular}


Organization: LLNL

Program: $\quad$ P.LLN.1110 Modeling and Analysis (LLNL)

Principal Investigator: David Chambers

Long Term Objectives:

This task involves the updating and utilization of computer codes and models in support of data analysis, system design, and experiment planning. The principle tasks are:

- Run 2D+time codes to support data analysis and experiment planning.

- Upgrade 2D+time codes to include turbulent wake generation of internal waves.

- Compare internal wave generation codes and models with laboratory data, upgrade models as required.

- Upgrade and refine source models for turbulent wake generation of internal waves.

- Run wind-wave relaxation code to update radar modulation model.

- Update clutter models for detection applications.

- Assess performance of new model-based processing approach to enhance wake images.

- Collect codes together into a single end-to-end simulator.

Short Term Objectives:

- Complete preliminary analysis of model-based

March 96 processing scheme applied to radar images

- Complete internal wave model upgrades

- Complete comparison with lab data

March 96

April 96

Accomplishments this reporting period:

Finished initial development of a general model-based processor for dispersive waves. Tested processor using both a processor-based simulator and a full simulation of an

internal wave wake.

Completed development of a current-wave interaction code. This determines the modulation of surface waves for a given surface current distribution. It is the last piece needing development before completing an end-to-end simulator.

Began reevalution of template generators for WCSEXP191 image. This is in response to some comments in the review meeting held at LLNL, Jan 25th.

Other Issues or Concerns:

Due to budget delay the restart of the wind-wave generation effort has been delayed.

This report is based on the first draft of the Work Unit Assignment, which was in effect during November. Subsequent reports will reflect the revised Work Unit Assignment sent in December when the revised WUAs are formally approved. No formal notification of WUA approval was received in January.

Project Budget Estimate (FY), Monthly Actual and YTD expenditures for WUA number P.LLN.1110:

\begin{tabular}{|c|c|c|c|c|c|c|c|c|c|}
\hline & \multicolumn{6}{|c|}{ DIRECT LABOR } & \multicolumn{2}{|c|}{ ODC } & \multirow{3}{*}{ TOTAL } \\
\hline & \multicolumn{2}{|c|}{ Management } & \multicolumn{2}{|c|}{ Technical } & \multicolumn{2}{|c|}{ Support } & \multirow{2}{*}{$\begin{array}{c}\text { Procure- } \\
\text { ment }\end{array}$} & \multirow[t]{2}{*}{ Travel } & \\
\hline & $\mathrm{M} / \mathrm{M}$ & Cost & $\mathrm{M} / \mathrm{M}$ & Cost & $\mathrm{M} / \mathrm{M}$ & Cost & & & \\
\hline $\begin{array}{l}\text { Project } \\
\text { Budget }\end{array}$ & 0 & 0 & TBD & TBD & 0 & 0 & TBD & TBD & TBD \\
\hline Actual & 0 & 0 & 0.0 & 0.0 & 0 & 0 & 6.5 & 3.8 & 10.3 \\
\hline YTD & 0 & 0 & 3.5 & 53.1 & 0 & 0 & 35.3 & 4.5 & 92.9 \\
\hline
\end{tabular}


Organization: LLNL

Program: $\quad$ P.LLN.1410 UCSB Wave Tank

Principal Investigator: James M. Brase

Long Term Objectives:

The UCSB Wave tank provides a capability for controlled test and evaluation of radar scattering models, image formation models, and modulation mechanisms, with realistic modulated ocean wave spectra. Three radar systems can be deployed at the wave tank: an LLNL radar covering 1.5 to $4 \mathrm{GHz}$, a UCSB radar covering 4-8 $\mathrm{GHz}$, and TRW radar covering 9-10 GHz.

In FY96 our objectives are to complete initial experiments on scattering from breaking and near-breaking waves (set $\mathrm{A}$ ), to extend the experiments to full windwave spectra (set B), and modulated by a surface current. (set $C$ )

\section{Short Term Objectives:}

- Complete characterization of wind wave spectra.

- Run preliminary Set B experiments with UCSB radar.

- Complete Set A experiments with LLNL radar upgraded to dual-polarization.

- Integrate high speed framing camera into surface truth diagnostics and synchronize with radars.

Accomplishments THIS reporting period:

- A full-day workshop on initial results from the UCSB wavetank was held as part of the UK/US program meeting. The meeting agenda is attached.

- UCSB presented results showing:

- consistent calibration of the radar signals and simulation of the calibration using geometric optics techniques

- initial results on polarization ratios and Doppler spectra

- LLNL presented analysis of an impulse radar ripples scattering experiment compared to Bragg resonant scattering theory. The results were simulated using a finite difference time domain technique.

Other Issues or Concerns: None

Project Budget Estimate (FY), Monthly Actual and YTD expenditures for WUA number P.LLN.1410:

\begin{tabular}{|c|c|c|c|c|c|c|c|c|c|}
\hline & \multicolumn{6}{|c|}{ DIRECT LABOR } & \multicolumn{2}{|c|}{ ODC } & \multirow{3}{*}{ TOTAL } \\
\hline & \multicolumn{2}{|c|}{ Management } & \multicolumn{2}{|c|}{ Technical } & \multicolumn{2}{|c|}{ Support } & \multirow{2}{*}{$\begin{array}{c}\text { Procure- } \\
\text { ment }\end{array}$} & \multirow[t]{2}{*}{ Travel } & \\
\hline & $\bar{M} / \mathrm{M}$ & Cost & $\overline{\mathrm{M} / \mathrm{M}}$ & Cost & $\bar{M} / \mathbf{M}$ & Cost & & & \\
\hline $\begin{array}{l}\text { Project } \\
\text { Budget }\end{array}$ & 0 & 0 & TBD & TBD & 0 & $\mathbf{0}$ & TBD & TBD & TBD \\
\hline Actual & 0 & 0 & 0.5 & 8.9 & 0 & 0 & 3.9 & 0.9 & 13.7 \\
\hline YTD & 0 & $\mathbf{0}$ & 1.0 & 21.4 & 0 & 0 & 374.8 & 1.0 & 397.2 \\
\hline
\end{tabular}


Organization: LLNL

Program: $\quad$ P.LLN.1420 Stratified Wave Tank

Principal Investigator: Harry Robey

Long Term Objectives:

To study the generation of internal waves by moving submerged bodies and their wakes in a controlled laboratory tank. The experimental results will be used to improve numerical models.

Short Term Objectives:

(1) perform experiments using liquid crystals to visualize IW patterns in a horizontal plane vs. time (this relates to the ability of a SAR to see non-stationary waves), and (2) perform a series of experiments using objects of various sizes to determine the scaling relations to be used to relate laboratory measurements to field results.

Accomplishments THIS reporting period:

The liquid-crystal visualization technique has been implemented in the tank over a $4 \mathrm{ft} \times 4 \mathrm{ft}$ area, and it works beautifully! Spheres run at low speed generated a very clear IW pattern attached to the sphere. Spheres towed at high speed showed initially only the turbulent wake, and then at a later time very clear IWs moving at a speed much lower than the sphere speed. This is in complete agreement with earlier results from this tank, and confirms visually that "wake-collapse" is not the mechanism of IW generation from the wake.

The scaling experiments using spheres of diameter 2", 4" and 6" are continuing in order to assess the scaling of the tank results to larger scale to allow comparison with field results. These experiments should be completed in March.

Other Issues or Concerns: None

Project Budget Estimate (FY), Monthly Actual and YTD expenditures for WUA number P.LLN.1420:

\begin{tabular}{|c|c|c|c|c|c|c|c|c|c|}
\hline & \multicolumn{6}{|c|}{ DIRECT LABOR } & \multicolumn{2}{|c|}{ ODC } & \multirow{3}{*}{ TOTAL } \\
\hline & \multicolumn{2}{|c|}{ Management } & \multicolumn{2}{|c|}{ Technical } & \multicolumn{2}{|c|}{ Support } & \multirow{2}{*}{$\begin{array}{c}\text { Procure- } \\
\text { ment }\end{array}$} & \multirow[t]{2}{*}{ Travel } & \\
\hline & $\mathrm{M} / \mathrm{M}$ & $\overline{\text { Cost }}$ & $\overline{M / M}$ & Cost & $\bar{M} / \mathrm{M}$ & Cost & & & \\
\hline $\begin{array}{l}\text { Project } \\
\text { Budget }\end{array}$ & 0 & 0 & TBD & TBD & 0 & o & TBD & TBD & TBD \\
\hline Actual & 0 & 0 & 1.2 & 16.8 & 0 & 0 & (56.3) & 0.0 & (39.5) \\
\hline YTD & 0 & 0 & 9.0 & 148.2 & 0 & 0 & 32.0 & 1.9 & 182.1 \\
\hline
\end{tabular}


Organization: LLNL

Program: P.LLN.1430 Institute of Applied Physics, Russia

Principal Investigators: Harry Robey

Long Term Objectives:

Continue experiments in the large thermo-stratified tank. Work will emphasize generation of internal waves in a stratified environment with shear.

\section{Short Term Objectives:}

(1) Finish the joint IAP-LLNL paper on internal wave generation by towed spheres for submission to the Journal of Fluid Mechanics. (2) Phase one of the experiments is now underway. These experiments will study in detail the interaction of the shear flow and the background stratified profile.

Accomplishments THIS reporting period:

Work is underway on phase one of the experiments. The report on phase one is due in two months.

The first draft of the joint IAP-LLNL paper has been sent back to IAP for final revisions. Following any revisions by IAP, the paper will be submitted to the ASAP office for approval prior to submission to Journal of Fluid Mechanics.

Other Issues or Concerns: None.

Project Budget Estimate (FY), Monthly Actual and YTD expenditures for WUA number P.LLN.1430:

\begin{tabular}{|c|c|c|c|c|c|c|c|c|c|}
\hline & \multicolumn{6}{|c|}{ DIRECT LABOR } & \multicolumn{2}{|c|}{ ODC } & \multirow{3}{*}{ TOTAL } \\
\hline & \multicolumn{2}{|c|}{ Management } & \multicolumn{2}{|c|}{ Technical } & \multicolumn{2}{|c|}{ Support } & \multirow{2}{*}{$\begin{array}{c}\text { Procure- } \\
\text { ment }\end{array}$} & \multirow[t]{2}{*}{ Travel } & \\
\hline & $\mathbf{M} / \bar{M}$ & Cost & $\mathbf{M} / \mathbf{M}$ & Cost & $\mathbf{M} / \mathbf{M}$ & Cost & & & \\
\hline $\begin{array}{l}\text { Project } \\
\text { Budget }\end{array}$ & 0 & 0 & TBD & TBD & $\mathbf{0}$ & 0 & TBD & TBD & TBD \\
\hline Actual & 0 & 0 & 0 & 0.0 & 0 & $\mathbf{0}$ & 60.0 & 0.0 & 60.0 \\
\hline YTD & 0 & 0 & 0 & 0.0 & 0 & 0 & 60.0 & 0.0 & 60.0 \\
\hline
\end{tabular}

This work was performed under the auspices of the Department of Energy by the Lawrence Livermore National Laboratory under contract W-7405-Eng-48. 
